\title{
Reproductive success and symmetry in zebra finches
}

\author{
JOHN P. SWADDLE \\ Behavioural Biology Group, School of Biological Sciences, University of Bristol \\ (Received 9 February 1995; initial acceptance 10 April 1995; \\ final acceptance 23 June 1995; MS. number: 4847)
}

\begin{abstract}
Fluctuating asymmetries are small, random developmental accidents in morphological traits that would otherwise be described as being bilaterally symmetric. Experimental evidence indicates that in mate choice situations individuals possessing symmetric arbitrary traits or symmetric secondary sexual characters are preferred over those with larger asymmetries. This experiment investigated the effect of symmetric and asymmetric arbitrary traits (arrangements of coloured leg-bands) on reproductive success in captive zebra finches, Taeniopygia guttata. Six groups of six males and six females were separated into six free-flight breeding aviaries. Nestboxes and nesting material were freely available throughout the experiment. Males wore symmetric and asymmetric arrangements of the same coloured leg-bands. Each male wore two orange and two light green bands, two on each leg. There were six possible arrangements of these leg-bands. One male from each of these six leg-band treatments was present in each aviary, along with six females wearing numbered orange bands. Symmetrically banded males produced more offspring that survived past the period of parental care than males in either of the asymmetric treatments; this appeared to be the effect of female choice processes and female-based parental investment and not male intra-sexual dominance. This is the first experiment to indicate that symmetrically manipulated males gain reproductive advantages in controlled laboratory conditions and further supports recent theories indicating the evolutionary importance of symmetry in signalling-trait design.

(C) 1996 The Association for the Study of Animal Behaviour
\end{abstract}

Fluctuating asymmetries are a measure of developmental stability in bilaterally symmetric traits and hence are a property of the genome as a whole (Van Valen 1962; Palmer \& Strobeck 1986; Zakharov 1989). They represent the ability of an individual to buffer development against random accidents and produce the intended, symmetrical phenotype. There are between-individual differences in this buffering capacity that may have a slight heritable component (Palmer \& Strobeck 1986; A. P. Møller \& R. Thornhill, unpublished data). In some cases, low levels of individual asymmetry (i.e. symmetry) are associated with indicators of high individual fitness (e.g. Beardmore 1960; Møller 1990; Harvey \& Walsh 1993; Swaddle 1994; Swaddle \& Witter 1994). It is also significant that levels of fluctuating asymmetries are much greater in secondary sexual

Correspondence: J. P. Swaddle, Institute of Biomedical and Life Sciences, Division of Environmental and Evolutionary Biology, Graham Kerr Building, University of Glasgow, Glasgow G12 8QQ, U.K. (email: gbza86@udcf.gla.ac.uk). traits than normal morphological traits, and so may be detectable during mate choice (Møller \& Pomiankowski 1993). As fluctuating asymmetry may reveal fitness-related information, it is possible that females are able to assess the quality of potential mates on the basis of male ornament asymmetry. There is field and laboratory experimental support for this notion (Møller 1992, 1993; Swaddle \& Cuthill 1994a, b). Only one study has reported a preference for asymmetry (Oakes \& Barnard 1994), but it confounded manipulations of symmetry with average trait size and so its results cannot be interpreted as a preference for asymmetry (Brookes \& Pomiankowski 1994).

My investigation focused on the reproductive behaviour of zebra finches, Taeniopygia guttata. These have proved to be a suitable model for studying behavioural aspects of mate choice in the laboratory in a number of studies (e.g. Burley et al. 1982; Burley 1986a, b; Clayton 1990; Houtman 1992; Swaddle \& Cuthill 1994a, b). Preferences observed in varying laboratory conditions have 
been shown to reflect mate choice preferences of non-captive zebra finches in their natural habitat (Burley 1988a). Previous investigations into the role of asymmetry in mate choice processes of zebra finches have indicated that females may prefer the most symmetrically ornamented males (Swaddle \& Cuthill 1994a, b). This predisposition is translated into a preference for both symmetric arbitrary traits and existing sexually dimorphic traits.

These investigations into the role of asymmetry in sexually selected behaviour of zebra finches were limited to female preferences in a choice chamber. Females preferred to perform ritualized courtship display jumps in front of males wearing symmetrically arranged leg-bands (Swaddle \& Cuthill 1994a) and males with symmetrically manipulated chest plumage (Swaddle \& Cuthill 1994b). Evidence from other studies suggests that these choice chamber preferences are likely to be highly related to actual mate choice and reproductive success. Burley found that individuals that were judged as being attractive in a choice chamber tended to have higher reproductive success, a higher proportion of same-sex offspring and lower mortality when housed in free-flight aviaries under the same experimental treatments (Burley 1985, 1986b).

By employing the same leg-band treatments as Swaddle \& Cuthill (1994a), I investigated the effects of ornament asymmetry on mate choice and reproductive success in six groups of captive zebra finches.

\section{METHOD}

Zebra finches are small estrildid finches that are essentially monogamous and form long-term pair bonds in the wild (Immelmann 1965) and in the laboratory (Burley 1986b). Both male and female contribute towards nest construction and parental care, although the female, on average, may contribute slightly more (Burley 1988b). Typically, incubation lasts for approximately 14 days. Once hatched, the young fledge after approximately 18 days; but are still dependent on parental feeding for a further 14-16 days.

I used 36 male and 36 female wild-type zebra finches. They were obtained as subadults from separate commercial breeders and so were not familiar with experimental birds of the opposite sex and had not bred before. Initially, all birds were maintained in single sex cages measuring approximately $0.5 \times 0.5 \times 1.0 \mathrm{~m}$ on a constant 14:10 h light:dark photoperiod at $15^{\circ} \mathrm{C}$ with food and water available ad libitum. Both males and females were randomly separated into six groups of six birds. Within each group, females were all given two orange leg-bands, one on each leg. One of these orange bands was numbered, hence allowing individual recognition. Within each group of six males, birds were randomly allocated to the six possible symmetric and asymmetric arrangements of two orange and two light green leg-bands, identical to those described in Swaddle \& Cuthill (1994a). Essentially, there were three treatment groups: symmetric, cross-asymmetric and asymmetric (refer to legend of Fig. 1 for more details). Within each treatment group both possible combinations of the four leg-bands were represented (refer to Swaddle \& Cuthill 1994a for more detail), hence giving the six combinations. The number of bands of each colour of leg-band was constant between treatments, only the symmetry of the arrangement differed. Each leg-band combination was worn by one male in each group.

The groups of six treatment-banded males were released into six free-flight, indoor aviaries measuring approximately $1 \times 1.5 \times 2.2 \mathrm{~m}$. In these aviaries, birds were maintained on a $14: 10 \mathrm{~h}$ light:dark photoperiod at a constant $15^{\circ} \mathrm{C}$ with ad libitum food, water and grit. Aviaries were in visual, but not acoustic, isolation. After 1 week, 12 hooded-basket nestboxes were placed at regular distances apart on the far wall of each aviary. Male activity was videotaped for $0.5 \mathrm{~h}$ in each aviary in an effort to quantify a male dominance hierarchy. After a further week, one group of six females was released into each aviary, so that each aviary contained six numbered females and six treatment-banded males. Again, activity in each aviary was videotaped for $0.5 \mathrm{~h}$ in order to ascertain levels and outcome of any male-male interactions. One week following the release of the females, fresh nesting material (dry grass and straw) was supplied to each aviary twice a week and so was constantly available. Millet spray was supplied at regular intervals.

Each nestbox was inspected approximately every other day between 1100 and 1400 hours for signs of nest building activity and the presence of eggs and nestlings. Nestlings were given a single numbered, orange leg-band after 11 days. 
Offspring were removed from the aviaries 21 days after fledging and kept in housing cages until their sex was determined by plumage appearance. Juvenile zebra finches develop adult plumage after approximately 12 weeks. I ascertained parentage of eggs and nestlings by observation of the nestbox and by catching the adults on the nest as they engaged in parental activities. It was not possible to estimate the incidence of extra-pair copulations or intraspecific brood parasitism in these breeding systems. I also recorded the number and identity of offspring fledging from nestboxes. Reproductive success was calculated as the number of offspring surviving at least 21 days past fledging, that is, slightly beyond the end of parental care.

From these observations I calculated several variables for each individual bird: number of eggs laid; number of eggs hatched; number of hatchlings that fledged; number and sex of fledglings that survived past parental care; latency to first successful nesting attempt (i.e. time to first clutch that hatched); and inter-clutch interval. This experiment lasted for approximately 10 months and terminated when one of the experimental females died. One of the leg-banded males died within the first 3 weeks of the experiment, before any nests had been constructed, and so was replaced by an extra male which came from a pool of reserves obtained from the same breeder at the same time as the experimental males.

I calculated dominance hierarchies between males within each aviary from the videotapes of male activity by subtracting the number of intrasexual agonistic interactions lost by a male from the number of interactions won (cf. Swaddle \& Witter 1994; Witter \& Swaddle 1994). Males were then ranked according to these values, 1 being the most dominant and 6 the least dominant. Interactions between males and females in the second tape were ignored as these encounters may not have been agonistic and were relatively infrequent compared with male-male interactions.

Six separate aviaries were constructed for this experiment to avoid the problem of pseudoreplication (Hurlbert 1984), as encountered by previous aviary studies of the reproductive behaviour of zebra finches (e.g. Burley 1986b). Each aviary, not each individual, was considered as a statistically independent data point. Previous investigations of the particular leg-band treatments used in this experiment in relation to mate choice indicated that there were no sided preferences within leg-band treatments (see Swaddle \& Cuthill 1994a). Therefore, I analysed the data just in terms of the three treatments: symmetric, cross-asymmetric and asymmetric using a mixed model ANOVA with leg-band treatment as a fixed effect and aviary as a random effect. I transformed the data, where appropriate, to ensure that residuals of analyses were normally distributed. All analyses were performed on MINITAB (Ryan et al. 1985) with an alpha level of 0.05 to minimize both type I and type II errors, whilst maintaining statistical power with these relatively small sample sizes. Two-tailed tests of probability are used throughout.

\section{RESULTS}

Symmetric males did not appear to establish a successful breeding nest before cross-asymmetric or asymmetric males $\left(F_{2,10}=2.77, P=0.110\right.$; Fig. 1a). However, there was a significant difference in reproductive success (number of offspring fledged that survived past parental care) between differently banded males $\left(F_{2,10}=5.66, P=0.030\right)$, symmetrically banded males having greater reproductive success than both asymmetric and cross-asymmetric males (Fig. 1b).

There may have been a slight difference between the number of eggs laid in nests occupied by males from different treatment groups $\left(F_{2,10}=4.01\right.$, $P=0.053$ ), indicating a small difference in reproductive investment; females mated to symmetric and cross-asymmetric males may have laid slightly more eggs than females paired with asymmetric males (Fig. 1c). This effect was non-significant and weak and, notably, there was no difference in average clutch size between treatment groups $\left(F_{2,10}=0.179, P=0.839\right)$ and no difference in interclutch interval (number of days between clutches that hatched) between differently banded males $\left(F_{2,10}=0.291, P=0.754\right)$.

This small difference in reproductive investment may, nevertheless, be related to reproductive success, unless egg size is related to clutch size. To control for this, I divided the data by the number of eggs produced. This gave data that were proportional to the number of eggs laid by each female and so may indicate differences between treatment groups that cannot be explained by between-female variation in initial reproductive 

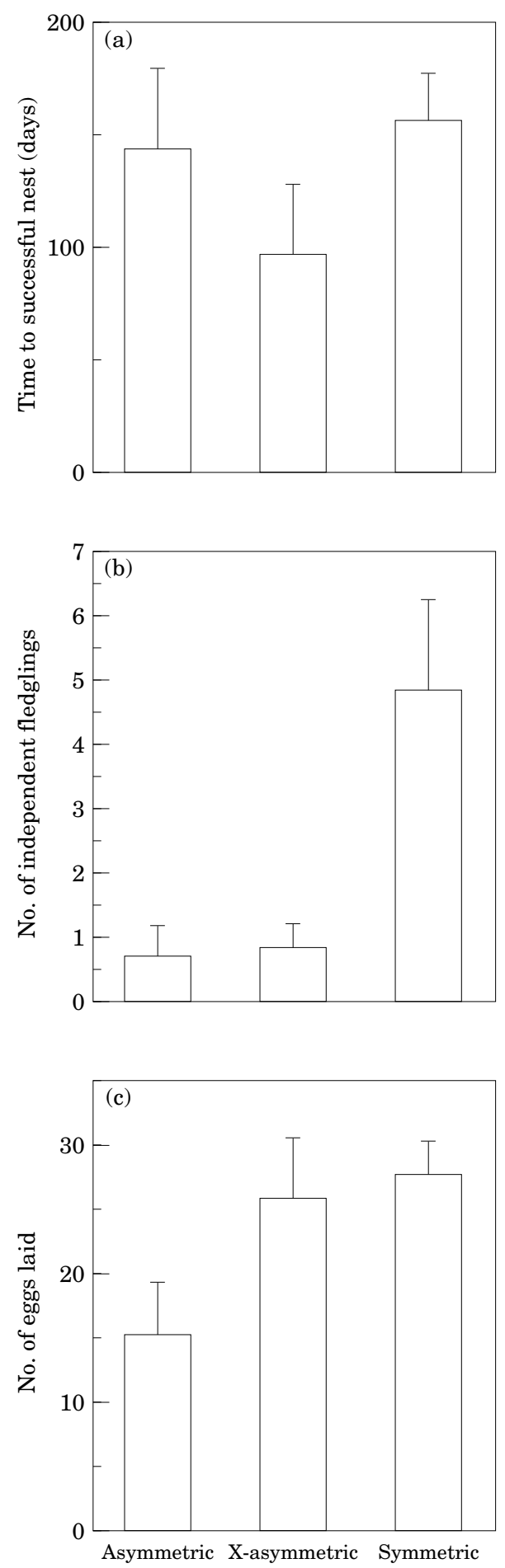

Leg-band treatment investment. All these analyses were performed on $(\ln +1)$ transformed data.

There were no differences in the proportion of eggs hatching (egg viability), or proportion of eggs laid that developed into fledglings, between leg-band treatments (egg viability: $F_{2,10}=0.310$, $P=0.740$; Fig. 2a; proportion eggs developing into fledglings: $F_{2,10}=3.06, P=0.092$; Fig. $2 b$ ), but symmetrically banded males had a higher proportion of eggs that developed into potentially viable offspring that survived past the period of parental care $\left(F_{2,10}=5.95, P=0.020\right.$; Fig. $\left.2 \mathrm{c}\right)$.

I analysed social dominance hierarchies by a nonparametric two-way analysis of variance (Siegel \& Castellan 1988). As there were two males from each leg-band treatment in each aviary, I averaged dominance ranks between these individuals. There was no difference in social dominance between leg-banded males either before the females were introduced to the aviaries (Friedman, $S=0.35$, $d f=2, P=0.838$; Fig. $3 \mathrm{a}$ ) or when the females were present (Friedman, $S=0.36, d f=2, P=0.834$; Fig. $3 \mathrm{~b})$. However, male dominance ranks before and after the release of females into the aviaries were correlated (Spearman rank correlation, $r_{\mathrm{S}}=0.750$, $N=18, P=0.014)$.

There was no difference in the sex ratio of successful offspring (i.e. those that survived past parental care) with respect to leg-band treatment (ANOVA on arcsine square-root of sex ratio data, $\left.F_{2,10}=0.210, P=0.814\right)$.

\section{DISCUSSION}

There was no difference in latency to a successful nesting attempt between leg-band treatments. In

Figure 1. Mean (+SE) (a) latency from introduction of females to successful nesting attempt; (b) number of fledglings that survived past parental care; (c) number of eggs laid by females mated to males from each leg-band treatment. Each male wore two light green and two orange plastic leg-bands, two on each leg in the six possible combinations. The six leg-band treatments were as follows $(\mathrm{G}=$ light green; $\mathrm{O}=$ orange). Two asymmetric treatments: left leg $=\mathrm{O}$ over $\mathrm{O}$, right $\operatorname{leg}=\mathrm{G}$ over $\mathrm{G}$; and left leg $=\mathrm{G}$ over $\mathrm{G}$, right $\mathrm{leg}=\mathrm{O}$ over $\mathrm{O}$. Two cross-asymmetric treatments: left leg $=\mathrm{G}$ over $\mathrm{O}$, right leg $=\mathrm{O}$ over $\mathrm{G}$; and left leg $=\mathrm{O}$ over $\mathrm{G}$, right leg $=\mathrm{G}$ over $\mathrm{O}$. Two symmetric treatments: left leg $=\mathrm{G}$ over $\mathrm{O}$, right leg $=\mathrm{G}$ over $\mathrm{O}$; and left leg $=\mathrm{O}$ over $\mathrm{G}$, right leg $=$ $\mathrm{O}$ over $\mathrm{G}$. 

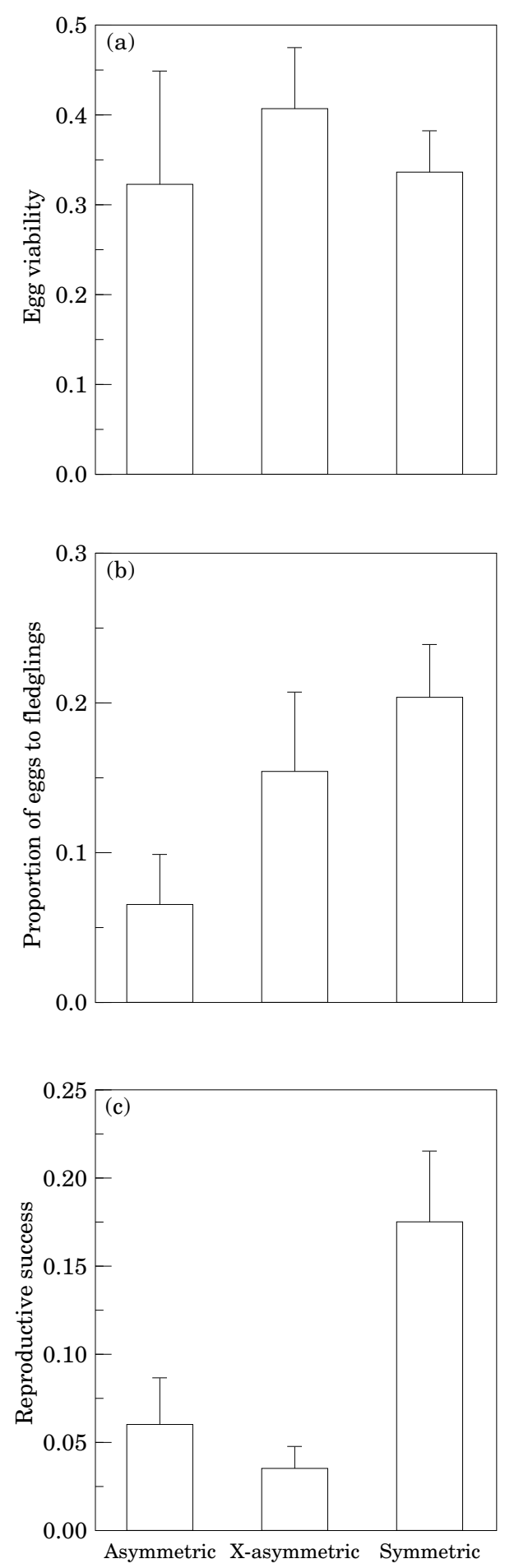

Leg-band treatment certain situations this may suggest that females are not choosing symmetric over asymmetric males. If symmetric males were preferred, one might expect them to obtain mates more quickly and start breeding earlier. However, this measure has previously been used as an indicator of female choice in the field where nest sites and resources are limited (e.g. Møller 1992, 1993). In my experimentally controlled situation, breeding sites were freely available and resources were not limited, and so nesting latency may not be a good indicator of female choice.

A more reliable indicator of selective female mate choice in such scenarios may be reproductive success, as breeding resources are equal. Higherquality females may be able to choose their mates before females of lower quality (Burley 1986c). Hence, the preferred males will obtain higherquality mates and may produce more offspring. Symmetric males produced more offspring that survived past the period of parental care than either asymmetric or cross-asymmetric males. This increase in reproductive success for symmetrically banded males was still present when a measure of reproductive effort (number of eggs laid by females) was controlled for (Fig. 2c). Hence, these data may indicate that symmetric males are chosen over asymmetric males. There is also strong evidence from choice chamber experiments that female zebra finches prefer symmetric males (Swaddle \& Cuthill 1994a, b).

It has also been postulated that females mated to attractive males may contribute relatively more parental care and work harder to rear their offspring than females mated to less attractive individuals (Burley 1986c; de Lope \& Møller 1993; Petrie \& Williams 1993). My results are also consistent with this hypothesis. The mates of symmetric (attractive) males did not lay significantly more eggs than cross-asymmetric or asymmetric males, indicating little variation in initial reproductive effort. These eggs were not more viable and did not produce offspring of discernible quality difference, as there was no difference in the proportion of eggs that hatched into fledging

Figure 2. Mean ( $+\mathrm{SE})$ (a) egg viability, proportion of eggs that hatched; (b) proportion of eggs that developed into fledging offspring; (c) reproductive success, proportion of eggs that developed into fledglings that survived past parental care for each leg-band treatment. 


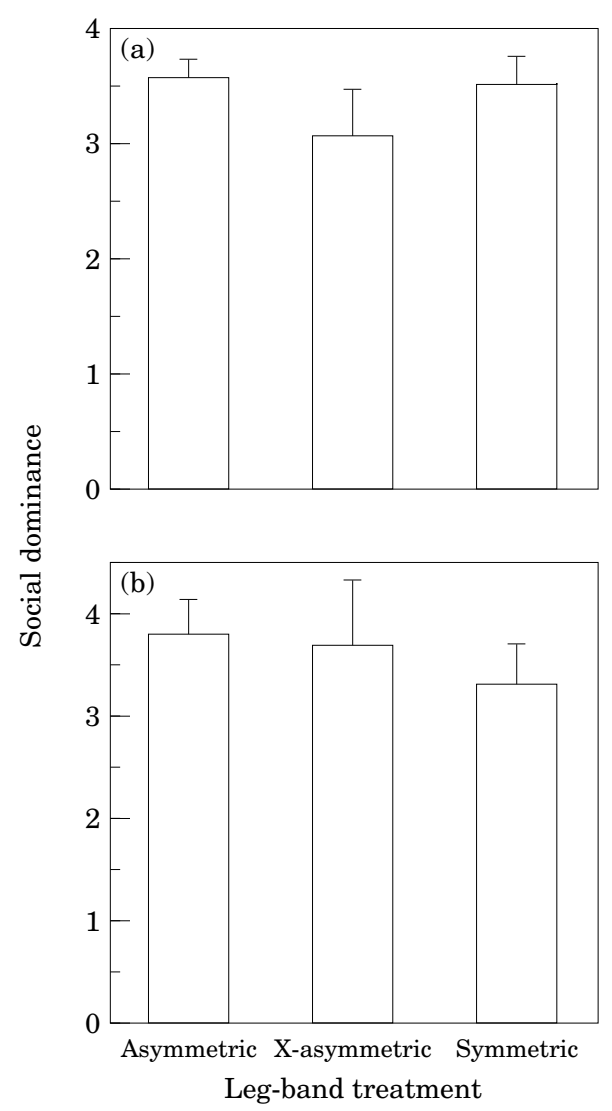

Figure 3. Mean $(+\mathrm{SE})$ dominance rank of males from the different leg-band treatments (a) before the females were introduced; (b) after release of the females into the aviaries.

offspring. Yet, symmetric males had higher reproductive success than either asymmetric or cross-asymmetric males.

This difference may have been due to differences in the level and quality of parental care given by the male and female. It is unlikely that there should be any systematic increase in parental care given by males wearing symmetric arrangements of leg-bands; in fact the opposite could be surmised (cf. Møller 1994). It is more probable that the female increased her level of parental effort, investing more in the offspring of an attractive mate, as has been shown for zebra finches with respect to leg-band colour per se (Burley 1986c). Observations and time-budgeting of parental activities were not possible in the present study, although future experiments could be devised to test this hypothesis more directly.

Leg-band symmetry did not appear to have any effect on social dominance amongst male zebra finches (Fig. 3a, b). This suggests that symmetry is not used in establishing and maintaining dominance hierarchies in male zebra finches. Similar results have been found in experimental studies of barn swallows, Hirundo rustica (Møller 1993) and European starlings, Sturnus vulgaris (Swaddle 1994; Swaddle \& Witter 1994, in press; Witter \& Swaddle 1994), although there is weak evidence to indicate a negative correlation between dominance and antler asymmetry in fallow deer, Dama dama (Malyon \& Healy 1994; but see Swaddle et al. 1995). Other investigations of social interactions amongst zebra finches have also indicated that dominance is not related to attractiveness in either sex (Burley 1986c; Ratcliffe \& Boag 1987). However, dominance ranks before and after the introduction of females were correlated, indicating that male zebra finches can establish relatively stable social dominance hierarchies, although the mechanisms of this social system are not known. It is also important to note that, as symmetry does not appear to alter the outcome of intra-sexual encounters, the effect of leg-band symmetry on reproductive success must occur through either inter-sexual female choice processes or femalebased parental investment and not through any male intra-sexual encounters.

There was no difference in the sex ratio of offspring that survived past parental care with paternal leg-band treatment. This does not provide support for the differential-allocation hypothesis (Burley 1988b), whereby it would be predicted that attractive (symmetric) males and mates of attractive males would be more likely to invest in offspring of their own (attractive) sex. Under this hypothesis, unattractive (crossasymmetric and asymmetric) males may favour the opposite sex or show an even sex ratio. The data reported here show no difference in offspring sex ratio between attractive and unattractive birds.

In summary, these data support some of the recent findings in behavioural ecology that indicate the importance of fluctuating asymmetry in sexual selection processes. Symmetrically banded males had higher reproductive success than crossasymmetric and asymmetric males. This effect is most likely to be manifest through female choice 
and/or females contributing increased levels of parental care towards offspring of attractive (symmetric) males. No matter which explanation is used, symmetric males had a reproductive advantage over asymmetric males. The manipulation employed in this experiment altered the symmetry of an arbitrary (artificial) trait and so conclusions concerning symmetry of existing sexually selected characters are limited, although there is strong evidence to suggest that female zebra finches do pay attention to symmetry in such traits and prefer symmetric males (Swaddle \& Cuthill 1994b). Even if the most conservative interpretation of these results is applied, that of a general pre-existing bias towards symmetric structures (see Swaddle \& Cuthill 1994a, b), these findings have significant evolutionary implications for the design of signalling traits. This study provides the first laboratory controlled evidence that symmetrically ornamented individuals have a reproductive advantage over their asymmetric competitors.

\section{ACKNOWLEDGMENTS}

I thank Innes Cuthill, Mark Witter and Rowan Lockwood for helpful discussion concerning experimental design and for inciteful discussion; Tim Guilford and two anonymous referees for their comments on an early version of the manuscript; Anders Møller for access to unpublished manuscripts; and Rob Massie and Sadie Iles for routine daily maintenance of the birds. I was funded by a S.E.R.C. research studentship and subsequently, a N.E.R.C. post-doctoral fellowship.

\section{REFERENCES}

Beardmore, J. A. 1960. Developmental stability in constant and fluctuating temperatures. Heredity, 14, 411-422.

Brookes, M. \& Pomiankowski, A. 1994. Symmetry and sexual selection: a reply. Trends Ecol. Evol., 9, 440.

Burley, N. 1985. Leg-band colour and mortality patterns in captive breeding populations of zebra finches. Auk, 102, 647-651.

Burley, N. 1986a. Comparison of the band-colour preferences of two species of estrildid finches. Anim. Behav., 34, 1732-1741.

Burley, N. 1986b. Sex-ratio manipulation in colorbanded populations of zebra finches. Evolution, $\mathbf{4 0 ,}$ 1191-1206.
Burley, N. 1986c. Sexual selection for aesthetic traits in species with biparental care. Am. Nat., 127, 415-445.

Burley, N. 1988a. Wild zebra finches have band-colour preferences. Anim. Behav., 36, 1235-1237.

Burley, N. 1988b. The differential allocation hypothesis: an experimental test. Am. Nat., 132, 611-628.

Burley, N., Krantzberg, G. \& Radman, P. 1982. Influence of colour-banding on the conspecific preferences of zebra finches. Anim. Behav., 30, 444-455.

Clayton, N. S. 1990. Mate choice and pair formation in Timor and Australian Mainland zebra finches. Anim. Behav., 39, 474-480.

Harvey, I. F. \& Walsh, K. J. 1993. Fluctuating asymmetry and lifetime mating success are correlated in males of the damselfly Coenagrion puella (Odonata: Coenagrionidae). Ecol. Entomol., 18, 198-202.

Houtman, A. M. 1992. Female zebra finches choose extra-pair copulations with genetically attractive males. Proc. R. Soc. Lond. Ser. B, 247, 3-6.

Hurlbert, S. H. 1984. Pseudoreplication and the design of ecological field experiments. Ecol. Monogr., 54, 184-211.

Immelmann, K. 1965. Australian Finches in Bush and Aviary. Sydney: Halstead.

de Lope, F. \& Møller, A. P. 1993. Female reproductive effort depends on the degree of ornamentation of their mates. Evolution, 47, 1152-1160.

Malyon, C. \& Healy, S. 1994. Fluctuating asymmetry in antlers of fallow deer, Dama dama, indicates dominance. Anim. Behav., 48, 248-250.

Møller, A. P. 1990. Fluctuating asymmetry in male sexual ornaments may reliably reveal male quality. Anim. Behav., 40, 1185-1187.

Møller, A. P. 1992. Female swallow preference for symmetrical male sexual ornaments. Nature, Lond., 357, 238-240.

Møller, A. P. 1993. Female preference for apparently symmetrical male sexual ornaments in the barn swallow Hirundo rustica. Behav. Ecol. Sociobiol., 32, 371-376.

Møller, A. P. 1994. Symmetrical male sexual ornaments, paternal care, and offspring quality. Behav. Ecol., 5, 188-194.

Møller, A. P. \& Pomiankowski, A. 1993. Fluctuating asymmetry and sexual selection. Genetica, 89, 267279.

Oakes, E. J. \& Barnard, P. 1994. Fluctuating asymmetry and mate choice in paradise whydahs, Vidua paradisaea: an experimental manipulation. Anim. Behav., 48, 937-943.

Palmer, R. A. \& Strobeck, C. 1986. Fluctuating asymmetry: measurement, analysis, patterns. A. Rev. Ecol. Syst., 17, 391-421.

Petrie, M. \& Williams, A. 1993. Peahens lay more eggs for peacocks with larger trains. Proc. R. Soc. Lond. Ser. B, 251, 127-131.

Ratcliffe, L. M. \& Boag, P. T. 1987. Effects of colour bands on male competition and sexual attractiveness in zebra finches. Can. J. Zool., 65, 333-338.

Ryan, B. F., Joiner, B. I. \& Ryan, T. A. 1985. MINITAB Handbook. 2nd edn. Boston, Massachusetts PWSKent. 
Siegel, S. \& Castellan, N. J. 1988. Nonparametric Statistics for the Behavioural Sciences. 2nd edn. Singapore: McGraw-Hill.

Swaddle, J. P. 1994. The Role of Fluctuating Asymmetry in Sexual Selection. Ph.D. thesis, University of Bristol.

Swaddle, J. P. \& Cuthill, I. C. 1994a. Female zebra finches prefer symmetric males. Nature, Lond., 367, 165-166.

Swaddle, J. P. \& Cuthill, I. C. 1994b. Female zebra finches prefer males with symmetrically manipulated chest plumage. Proc. R. Soc. Lond. Ser. B, 258, 267-271.

Swaddle, J. P. \& Witter, M. S. 1994. Food, feathers and fluctuating asymmetry. Proc. R. Soc. Lond. Ser. B, 255, 147-152.
Swaddle, J. P. \& Witter, M. S. 1995. Chest plumage, dominance and fluctuating asymmetry in female starlings. Proc. R. Soc. Lond. Ser. B, 260, 219 223.

Swaddle, J. P., Witter, M. S. \& Cuthill, I. C. 1995. Museum studies measure FA. Anim. Behav., 49, 1700-1701.

Van Valen, L. 1962. A study of fluctuating asymmetry. Evolution, 16, 125-142.

Witter, M. S. \& Swaddle, J. P. 1994. Fluctuating asymmetry, competition and dominance. Proc. R. Soc. Lond. Ser. B, 256, 299-303.

Zakharov, V. M. 1989. Future prospects for population phenogenetics. Soviet Sci. Rev. F. Physiol. Genet. Biol., 4, 1-79. 